\title{
Re-Validating Weak-Form Hypothesis in Nigerian Capital Market: A Comparative Test Analyses
}

\author{
Ajibola Arewa $^{1} \&$ Prince C Nwakanma ${ }^{2}$ \\ ${ }^{1}$ Lagos State University, Faculty of Management Sciences, Lagos, Nigeria \\ ${ }^{2}$ Faculty of Management Sciences, University of Port-Harcourt, River State, Nigeria \\ Correspondence: Ajibola Arewa. Department of Accounting and Finance, Faculty of Management Sciences, \\ Lagos State University, Lagos, Nigeria. Tel: 080-6096-2048. E-mail: ajibolaarewa@yahoo.com
}

Received: December 16, 2013

Accepted: February 11, 2014

Online Published: March 26, 2014

doi: $10.5539 /$ ibr.v7n4p73

URL: http://dx.doi.org/10.5539/ibr.v7n4p73

\begin{abstract}
In the study, we adopted comparative statistical techniques to evaluate the behaviors of stock returns in Nigerian Capital market. Data were collected from CBN statistical bulletin over a period of Jan 1985 to Dec 2012. Our findings based on $\mathrm{JB}, \mathrm{BJ}$, portmantuea autocorrelation and LM serial correlation tests showed that the behaviors of stock returns follow the pattern of a random walk or alternatively the steps of a man who is drunk, while the K-S, Runs and unit root tests contradict this position. Therefore we conclude that the controversial issue on the tests of RWH in Nigerian stock market strikingly relies on the techniques that are applied and the asymptotic nature of data set.
\end{abstract}

Keywords: RWH, efficiency, drinker, market, Nigeria

\section{Introduction}

We are all well familiar with the expressions "There's no free launch" and with regards to mutual bargaining "You get what you pay for" these expressions are commonly replicated in our daily conversation for the simple fact that the entire world is complex and full of competitive investors who are well informed or economically self interested in security price changes. They know that the price of a security tends to reflect its true equilibrium value (that is its relation to other assets' prices). Like other markets, stock market is some times riddle with unimaginable competition which is less or almost unnoticed by market participants. This issue has attracted enormous amount of theoretically and empirically research guides principally by the tenets of the Efficient Market Hypotheses (EMH).

The concept of EMH is one of the most important and pervasive as well as debatable issue in the modern theory of finance (Fama, 1970, 1991). This is because the hypothesis presents in a general term, the consequence of competition on the capital market in determining the equilibrium values of financial assets. However, a market is said to be efficient if prices fully reflect all available information and the level of efficiency of a market can be tested using three models: the fair Game model, the Submartingale Model and the Random Walk Model (Fama, 1970). Also, according to Fama, EMH can be categorised into three level based on the definition of the available information sets, namely weak form, Semi-Strong form and the Strong form. Following the work of Fama and others the EMH has been really investigated in both the developed and emerging markets; especially, in the emerging markets, most empirical studies have focused on weak form of market efficiency, for instance, Dickson and Muragu (1994) provided evidence which showed that Kenyan stock market was weak form efficient. However, Parkinson's (1984) study contradicted the position of Dickson and Muragu. In the same token, Gupta and Basu (2007) concluded that the weak form hypothesis did not significantly hold in Indian stock market. The test conducted on a group of Asian markets revealed that the markets of Japan and Taiwan were weak form efficient; while those of Indonesia, Malaysia and Philippines were found to be inefficient but Singaporean and Thai markets have become efficient after the Asian crisis (Kim \& Shamsuddin, 2008). Liu (2010) found that the Chinese stock mark was not efficient in the weak form. Apart from this generally mixed evidence, a central feature is that most of the existing studies are conducted through the use of conventional weak form testing techniques such as serial correlation test, whose robustness has been empirically questioned elsewhere (see, Hsich, 1991). 
In Nigeria, stock exchange has been in operation since 1960. Olowe (1999) has investigated the weak form efficiency in the price series of a number of selected stocks listed in the Nigerian Stock Exchange (NSE). The study did not reject the notion of weak form market efficiency in Nigeria. Currently, the use of serial correlation test whose robustness has been questioned in the literature, is a striking feature, raising substantial doubt as to whether Olowe's result will hold in the face of an empirically well-specified methodology like the Lo and Mackinlay's $(1988,1989)$ parametric variance ratio test. A more compelling basis was provided by Wright (2000) who proposed the use of a non-parametric alternative. In a more recent time, the statistical applications adopted by Belaire, French and Opong (2005a, 2005b) and chang Fok, and Lung (2006) provided robust evidence which was methodologically consistent with that of Wright. Additionally, market microstructure theory suggests that increase in market capitalization and membership among others can lead to procurements in treading efficiency (Amihud, Mendelson, \& Lauterbach, 1997). Rapuluchukwu (2010) provided substantial evidence in support of Olowe but however, Inegbedio (2009) as well as Aguegbo, Adewole and Maduegbuna (2010) concluded that the Nigerian stock market is not information ally efficient. Therefore, there have been considerable developments on the tests of weak form efficiency of the Nigerian capital market. It is important to know that Nigerian investors are guided by the sentiments of faith and phobia and since they are rationally economic agents, they like to play safe by investing their hard-earning money optimally. These investors look for organized information and logical reasoning backed by scientific methods and techniques. Since the two prime constellations of judicious investors are the risk and return inherently present in securities, therefore, guidance on selecting the right investments based on scientific methods would be a boom to the investors.

This study seeks to empirically revalidate the Nigeria market in the weak form efficiency using monthly data to cover a period of 24 months ranging from 2009 to 2010. In doing so, it makes significant contribution to the existing literature. First, it adopts three statistical tests - the serial correlation test, the Run test and the parametric variance ratio test to examine the efficiency status of Nigerian stock market; second, unlike some of the prior studies that offer evidence by analysing only the price series of sample of individual stocks this study provides conclusive evidence using the price series of all share market index at different Lagged autoregressive model. Thirdly, it extends the existing evidence by using the most recently available data. Finally, it unambiguously investigates the random walk hypothesis with the aim of re-examining the prior positions in the literature with regard to the efficiency of the Nigerian stock market. The remainder of the paper is organized as follows: Section 2 reviews some of the previous literature on EMH, section 3 describes the data and research methodology, and section 4 presents empirical results, while conclusion and recommendations are highlighted in section 5 and 6 respectively.

\section{Literature Review}

The principal notion behind the EMH is that stock prices adjust rapidly to the new information and thus current prices fully reflect all available information (Fama, 1970). EMH is an important concept, both in terms of an understanding of the working stock and in their performance and contribution to the development of a country's economy. If the stock market is efficient, the prices of stocks will represent the intrinsic value of the stock market and in turn, the secured savings will be optimally allocated to productive investments in a way that benefits both individual investors and the country economy (Copeland \& Weston, 1988).

The efficient market theory further asserts that if markets are efficient, then it should be mutually impossible for an investor to outperform the market on a sustainable basis. Even though variation will occur and there will be problems when securities are over or undervalued these anomalies are expected to disappear as quickly as they appear, thus, making almost impossible to profit from them consistently. However, Fama (1970) formalized the theory of efficient market, organized empirical evidence on and divided the EMH into three sub-hypotheses - the weak form, the semi-strong form and the strong form hypotheses-depending on the information set involved. Our primary concern in this study is the weak form hypothesis. Therefore the relevant literature on this subject is reviewed as follows.

The weak form of market efficiency theorizes that the current prices of stocks do not reflect fair values and are only reflections of past prices. It further states that the future price can not be predicted using either the past or current prices. This is alternatively known as independence hypothesis or Random Walk Hypothesis (RWH). The empirical testing of this RWH was initially mixed. Early studies by Fama (1965), Sameulson (1965) and Working $(1934,1960)$ examined it and could not refute a random walk. RWH were tested heavily in both developed and developing markets. The developed markets were found to be weak form efficient. This means that successive returns are independent and follow random walk (Fama, 1965, 1970). The results of weak-form efficiency are confirmed considering a low degree of serial correlation and transaction cost (Cootner, 1962; Fama, 1965; Kendall, 1943, 1953; Osborne, 1962). All these research works support the proposition that price 
changes are random and past changes are not useful in forecasting future price changes particularly after transaction cost is taken into account. Though the studies of Fama and French (1988); Fama (1991); Granger (1975); Hawawini (1984); Lo (1997); Roterba and Summers (1988) confirmed the weak form, yet they could not guide the investors with any clear-cut trading rules to make abnormal profits.

In Africa, Samuels and Yacout (1981) and Parkinson (1984) were among the first to use serial correlation tests to examine the weak form efficiency, albeit they provided satisfactory evidence. While the result of Samuels and Yacout accented the notion of weak form market efficiency in weekly prices of 21 listed Nigerian firms from 1977 to 1979 that of Parkinson rejected it in monthly price series of 30 listed Kenyan firms from 1974 to 1978. Dickson and Muragu (1994) applied run and serial correlation tests to investigate whether stock prices behaviour of 30 listed companies on the Nairobi Stock Exchange (NSE) from 1979 to 1988 were weak form efficient. In contrast to the evidence of Parkinson, they demonstrated that successive price changes were independent of each other for majority of the companies investigated.

In 2003, Appiah-Kusi and Menya applied the EGACH-M model to examine the weak form efficiency in weakly prices series of eleven African stock market indices. Their results confirmed previous evidence that equity markets in Egypt, Kenya, Morocco, Mauritius and Zimbabwe were weak form efficient, while those of Botswana, Ghana, Ivory Coast, Nigeria, South Africa and Swaziland were not efficient in the weak form. Also, Simons and Laryea (2004) investigated the efficiency of some stock markets including - Ghana, Egypt Mauritius and South Africa from 1990 to 2003, applying serial correlation, run, and the multiple variance-ratio tests. In congruence with previous studies, their results indicated that apart from South Africa, the index price behaviours of the markets analysed were weak form inefficient. Elango and Hussein (2008) employed daily indices of Gulf Co-operation Council (GCC) countries' stock markets and found that the hypothesis of market weak-form efficiency did not hold. Therefore, they affirmed that the GCC stock markets should be integrated to improve their efficiencies. Mishra, Das and Pradhan (2009) applied unit root tests on a given sample of Bombay Stock Exchange (BSE) daily stock index and confirmed that stock prices were independent on one another and therefore they displayed random pattern in their movements. The study of Hameed and Ashraf (2009) revealed that the historical information about future expected prices helps in guessing the riddles of the capital market and there was convincing evidence that the investors that shouldered high risk made substantial gains. Richard, Suchi and Ranghunandan (2010) investigated the information efficiency of the Nigerian stock market using 2003 SEC regulation fair disclosure. Specifically they made comparison of four quarters before and after the regulation and concluded that after this regulation, stock market efficiency improved considerably. Hamid, Suleman, Shah and Akash (2010) employed the Runs, Unit Root, Autocorrelation, and Ljung-Box Q-statistic Tests on monthly data of the stock market of the Asia-Pacific region for the period over January 2004 to December 2009 and confirmed that the market follows a random walk phenomenon. Kormaz and Akman in 2010 selected two indices from Istanbul Stock Exchange (ISE). They carried out their analysis using unit root and co-integration tests. Overall their finding revealed that there was no presence of co-integration among the selected indices and such concluded that ISE was Weak-form efficient.

\subsection{Prior Statistical Tools Applicable in the Literature}

It is quite obvious that a wide variety of statistical tests have been used in the literature to examine or re-examine the empirical validity of the weak form hypothesis. These tests are grouped into two: we have the parametric and the non-parametric tests. The parametric test is essentially relating to the serial correlation test which involve estimating Auto Regression model (AR) or Auto Regression Integrated Moving Average (ARIMA). Either of these warrants assumption of normality of the distributions. The non-parametric tests includes the runs and the variance ratio tests, both are respectively introduced by Reilly and Brown (2003), Lo and Mackinlay (1988). These tests are used to testing the randomness in the true senses of stock prices taking into consideration the problem of heteroscedasticity. However, of late simulation tests are also used in testing the efficient market hypothesis. Simulation tests generate a random series of numbers as returns and compare them with the actual price changes in the market. The similarity between the parametric and non-parametric tests establishes the relevance of technical analysis as a stock market price predictor since random numbers can be generated to know the future movement of prices. Thus, a wide variety of both parametric and non-parametric tests are used in examining the efficiency of the stock market. We follow this trend in this present study. First of all we use the unit root test to ascertain the stationarility of stock return series and then adopt the Auto Regressive (AR) and runs techniques to examine the behaviour of stocks in the Nigerian Capital market. 


\section{Data and Methodology}

\subsection{Data}

We used the monthly aggregate price index (i.e., the market index) obtained from CBN statistical bulletin over a period of Jan 1985 to Dec 2012. The index was used to compute the return of the stock market at a given time. Functionally, the market return is expressed as:

$$
R m t=\frac{C M I t-B M I t}{B M I t}
$$

Where: $\mathrm{Rmt}$ is the aggregate market return at month $(\mathrm{t})$;

$\mathrm{CMI}_{\mathrm{t}}$ is the closing market index at month $(\mathrm{t})$;

$\mathrm{BMI}_{\mathrm{t}}$ is the beginning market index at month $(\mathrm{t})$.

\subsection{Methodology}

\subsubsection{Parametric Model}

The model adopted in this study shows the independency or dependency between/among successive stock market returns, and it takes its lead from the works of Claessens, Dasgupta and Glen (1995), Kendall (1943), Laurence (1986), Poshakwaleb (1996), Micolaas (1997), Nourredine and Khaba (1998). However, it is stated as follows with little modification.

$$
R m_{t}=y_{o}+y_{1} R m_{t-1}+y_{2} R m_{t-2}+\ldots \ldots+y_{n} R m_{t-n}+u_{t}
$$

Where: $\mathrm{Rm}_{\mathrm{t}}$ is the return on market at current period;

$\mathrm{Rm}_{\mathrm{t}-1}$ is the lag one-return;

$\mathrm{Rm}_{\mathrm{t}-2}$ is the lag two-return;

$\mathrm{n}$ is the lag operator.

Based on this model, we hypothesize that:

1) The returns on Nigerian Capital market follow a normal distribution.

2) The returns on Nigerian Capital market are randomly distributed.

The reason for testing normality is due to the fact that unless the time series data are normal or stationary, any parametric test such as serial correlation test will yield spurious or nuances cal results.

\subsubsection{Non-Parametric Model}

We used the Runs test of Siegal (1956). According to him a "Run" is defined as "a succession of identical symbols which are followed or preceded by different symbols or no symbol at all". The number of Runs is computed as a sequence of the price changes of the same sign (such as:,,++- oo). When the expected number of run is significantly different from the actual number of runs, we reject the null hypothesis that the stock market returns are randomly distributed. As reported by Poshakwale (1996) "a lower than expected number of Runs indicates market's over reaction to information, subsequently reversed, while higher number of Runs reflects a lagged response to information. Either situation would suggest an opportunity to excess return"

The Run test has advantage over the serial correlation test because it does not require returns to be normally distributed. It therefore provides a strong alternative to the parametric serial correlation test in which returns are assumed to be normal. To perform the run test, both the expected runs and the actual runs are computed for a given sample of returns.

The expected number of run is given by

$$
E(R)=\frac{n+2 n a n b}{n}
$$

Where: $\mathrm{E}(\mathrm{R})$ is the expected number of Runs;

$\mathrm{n}$ is the number observations;

while $n_{a}$ and $n_{b}$ are number of observations above and below the sample mean or median and $R$ represents the observed number of runs. 
The standard error can be stated as:

$$
\delta(R)=\left[\frac{2 n_{a} n_{b}\left(2 n_{a} n_{b}-n\right)}{n 2(n-1)}\right]^{1 / 2}
$$

Where: $\delta(\mathrm{R})$ is the standard error.

The asymptotic or approximately normal Z-statistic is expressed as:

$$
Z(R)=\frac{R-E(R)}{\delta(R)}
$$

Where: $\mathrm{Z}(\mathrm{R})$ is the $\mathrm{Z}$-statistics.

\subsubsection{Kolmogorov-Smirnov Model Specification}

Kolmogorov (1933) and Smirnov (1948) interpedently developed the Kolmogorov-Smirnov test for normality and it can be defined as:

$$
\begin{gathered}
Z_{k-s}=\max \left[\frac{F\left(X_{i}\right)-i-1}{N}, \frac{i-F\left(X_{i}\right)}{N}\right] \\
1 \leq \mathrm{i} \leq \mathrm{N}
\end{gathered}
$$

Where: $Z_{\mathrm{K}-\mathrm{S}}$ represents the Z-Statistic for K-S Tests;

$X_{i}$ is the series under investigation;

$\mathrm{F}$ is the theoretical cumulative distribution of the distribution being tested.

\subsubsection{Jarque-Bera Model Specification}

Bera and Jarque (1981) formalized a specification that was rooted on the coefficients of total skewness and kurtosis which are expressesd as:

$$
\begin{aligned}
& S k=\frac{E\left(U^{3}\right)}{(\delta 2)^{3 / 2}} \\
& K t=\frac{E\left(U^{4}\right)}{(\delta 2)^{2}}
\end{aligned}
$$

Where: Sk is the skewness coefficient;

$\mathrm{Kt}$ is the kurtosis coefficient;

$\mathrm{E}(\mathrm{U})$ and $\delta^{2}$ are the mean and variance of the series respectively.

Based on equations 7 and 8, The Jarque Bera specification can be expressed as:

$$
Z_{J B}=\left[\frac{N S k^{2}}{6}+\frac{(K t-3)^{2}}{24}\right]
$$

Where: $Z_{\mathrm{JB}}$ implies computed z-statistic for the Jarque Bera Test;

$\mathrm{N}$ is the sample size.

\subsubsection{Box Jenkin Q Statistic Specification}

The BJ statistic was credited to Box and pierce (1970) and Ljung and Box (1978) as a portmanteau test for linear dependence in time series and it can be expressed as:

$$
Q^{*}=\frac{T(T+2) \sum_{L=1}^{N} A_{L}^{\wedge \sim} X_{N}^{2}}{T-L}
$$

Where: Q* implies the computed statistic for the $\mathrm{BJ}$;

$\mathrm{T}$ is the sample size;

$\mathrm{N}$ is the maximum lag length;

$\mathrm{L}$ is the lag operator;

$\mathrm{A}_{\mathrm{L}}$ is the Autocorrelation coefficient at a given lag length which is given. 
as:

$$
A_{L}^{\wedge}=\frac{\sum_{i=1}^{n-L}\left(X_{i^{-}} E(X)\right)\left(X_{i+L^{-}} E(X)\right)}{\sum_{i=1}^{n}(X i-E(X))^{2}}
$$

Where: $X_{i}$ is the series under investigation;

$E(X)$ is the expected value or mean of the series.

\subsubsection{Test for Stationarity}

The Augmented Dickey-Fuller (ADF) and Philips-Peron (PP) have been thoroughly discussed in the literature including the Kwaiatowski, Phillips-Schmidt and Shin (KPSS) as tests for a unit root. In summary the specification can be expressed as:

$$
\Delta R_{t}=a_{0}+a_{1} t+b_{0} R_{t-1}+\sum_{i=1}^{k} b_{i} \Delta R_{t-1}+\mu_{t}
$$

Where: $\mathrm{R}_{\mathrm{t}}$ and $\mathrm{R}_{\mathrm{t}-1}$ signify present and previous value of return series;

$\Delta R_{t}=R_{t}-R_{t-1}$, b's are the parameters to be estimated, $k$ is the maximum number of lagged terms, $t$ is the trend term which may be included or not depending on the assumption under which the test is being conducted; $\lambda_{1}$ is the estimated coefficient of trend, $\lambda_{0}$ is the constant and $\mu_{\mathrm{t}}$ is the white noise.

\section{Results}

Most of the researchers who tested the RWH in Nigerian stock market employed serial correlation technique and in some cases they conducted subjective analyses like questionnaire, amidst score of powerful techniques. Therefore their conclusions may be imprecise and needed to be revalidated. To accomplish this task, we utilized a battery of tests as discussed below.

\subsection{Unit Root Tests}

The tests of a unit root in a series reveal the level of its stationarity or otherwise. In this study, we conducted the ADF, PP and KPSS tests on the index of Nigerian stock market. The results of these tests are summarized in Table 1.

Table 1. The unit root test results based on ADF, PP and KPSS

\begin{tabular}{lllllll}
\hline Variable Series & ADF-Stat & $\mathrm{TCV}_{1} @$, 5\% & PP-Stat. & $\mathrm{TCV}_{2} @$, 5\% & KPSS & $\mathrm{TCV}_{3} @$, 5\% \\
\hline $\operatorname{Rmt}(0)$ & -3.99 & -2.98 & -3.93 & -2.98 & 0.34 & 0.46 \\
\hline
\end{tabular}

Note. $\mathrm{TCV}_{1}, \mathrm{TCV}_{2}$ \& $\mathrm{TCV}_{3}$ indicate Test Critical Value for ADF, PP and KPSS respectively; while Rmt( $(0)$ means the series of market at level. Source: Extracted from E-view Window 7.

The results imputed in Table 1 show that the absolute values of ADF (3.99) and PP (3.93) are larger than the critical value (2.98). Therefore, the null hypothesis that there is presence of a unit root can be rejected. Also, we corroborate these tests with the KPSS whose null hypothesis is that there is no presence of a unit root. Since the KPSS statistic (0.34) is less than the critical value (0.46), we can not reject this null hypothesis. Hence, it is amazingly striking that the three tests provide overwhelming evidence in support of the series being stationary at level. We can infer here that returns on the Nigerian stock market are relatively stable debunking the popular claim of the RWH.

\subsection{Normality Test}

We employed the Jarque-Bera test to investigate whether there are anomalies in the market which investors can take advantage off to outperform the market or any other player(s). See the summarised results in Table 2.

Table 2. Normality test results

\begin{tabular}{lllllll}
\hline Series & Mean & Std. Dev & Skewness & Kurtosis & JB & PV \\
\hline Rmt & 0.23 & 0.30 & 0.87 & 5.77 & 12.54 & 0.00 \\
\hline
\end{tabular}

Source: Extracted from E-view Window 7. 
The mean value of the series as revealed in Table 2 is approximately 0.23 , positive but very small. This indicates that the returns on the market display an increasing tendency over the study period. However, the returns are volatile as revealed by the value of the standard deviation (0.30), positively skewed and leptokurtic in nature. The Jarwque-Bera (JB) statistic is 12.54 and its corresponding probability value is 0.00 implying that the null hypothesis of normality is rejected. Therefore, the return generating-process of the market is not normally distributed and it follows the pattern of a random frame-walk or steps of a drinker.

\subsection{Parametric Test}

The estimated value of the autoregression equation (2) and its test for significance represent the parametric test adopted in this study. The results are found in Table 3.

Table 3. Estimated value of equation 2

\begin{tabular}{lcl}
\hline Variable & coefficient & t-value \\
\hline $\operatorname{Rmt}(-1)$ & 0.27 & $(1.11)$ \\
$\operatorname{Rmt}(-2)$ & -0.19 & $(-0.74)$ \\
$\operatorname{Rmt}(-3)$ & 0.06 & $(0.24)$ \\
$\operatorname{Rmt}(-4)$ & 0.02 & $(0.06)$ \\
$\operatorname{Rmt}(-5)$ & 0.02 & $(0.06)$ \\
\hline
\end{tabular}

Source: Extracted from E-view Window 7.

The results in Table 3 show the relationship between the current and previous returns on the market up to lag 5 . All the absolute values of the observed t-statistics are by far less than the critical t-statistic $5 \%(1.72)$. Therefore, we can assert that there is no significant relationship between the present return and past returns which is in tandem with the random walk preposition; no investor can significantly predict the variations exhibiting the movements of market returns.

\subsection{Diagnostic Tests}

We diagnosed the autoregression equation (2) for autocorrelations and serial correlations. The results are reported in Tables ( $4 \mathrm{a}$ and $4 \mathrm{~b})$ respectively.

Table 4a. Portmateau tests for autocorrelations

\begin{tabular}{llllll}
\hline Lags & Q-Stat & Prob. & Adj Q-Stat & Prob. & df \\
\hline 1 & 0.002767 & NA* & 0.002893 & NA* & NA* \\
2 & 0.004922 & NA* & 0.005253 & NA* & NA* \\
3 & 0.005900 & NA* & 0.006378 & NA* & NA* $^{*}$ \\
4 & 0.008022 & NA* & 0.008946 & NA* & NA* \\
5 & 0.012442 & NA* & 0.014594 & NA* $^{*}$ & NA* $^{*}$ \\
6 & 0.036691 & 0.9818 & 0.047401 & 0.9766 & 2 \\
\hline
\end{tabular}

Source: Extracted from E-view Window 7.

It is observed in Table 4a that the Q-statistic (0.04) and the Adj Q-statistic (0.05) both at lag 6 are far less than the Chi-squared statistic (5.99) at 5\% based on $\mathrm{df}(2)$ meaning that null hypothesis of no residual autocorrelations cannot be rejected. Additionally, Table $4 \mathrm{~b}$ reveals that all the LM statistics are less than the Chi-squared statistic (3.84) at $5 \%$ based on $\mathrm{df}(1)$. Again, the null hypothesis of no serial correlations cannot be rejected. These are significance evidence that successive error terms are not serially correlated/ dependent and their variances are constant. The absences of autocorrelations and serial correlations support the evidence of random walk movements in the market. 
Table 4b. Langrager multiplier serial correlation test

\begin{tabular}{lcc}
\hline Lags & LM-Stat & Prob \\
\hline 1 & 0.391726 & 0.5314 \\
2 & 0.307588 & 0.5792 \\
3 & 0.049508 & 0.8239 \\
4 & 0.043587 & 0.8346 \\
5 & 0.046582 & 0.8291 \\
6 & 0.027194 & 0.8690 \\
\hline
\end{tabular}

Source: Extracted from E-view Window 7.

\subsection{Test for Linear Dependency}

In this study, we employed the Box-Jenkin statistics to estimate the linear dependency of the serial of returns as reported in Table 5.

Table 5. Results of the Box-Jenkin staistics

\begin{tabular}{|c|c|c|c|c|c|c|}
\hline Autocorrelation & Partial Correlation & & $\mathrm{AC}$ & PAC & Q-Stat & Prob \\
\hline.$|* *|$. & $.||^{* *} \cdot \mid$ & 1 & 0.219 & 0.219 & 1.4970 & 0.221 \\
\hline$\cdot *|\cdot|$ & $*|\cdot|$ & 2 & -0.118 & -0.174 & 1.9460 & 0.378 \\
\hline$\cdot|\cdot|$ & $\cdot|\cdot|$ & 3 & -0.011 & 0.063 & 1.9500 & 0.583 \\
\hline$\cdot|\cdot|$ & $\cdot|\cdot|$ & 4 & 0.045 & 0.012 & 2.0196 & 0.732 \\
\hline$\cdot|\cdot|$ & $\cdot|\cdot|$ & 5 & 0.019 & 0.010 & 2.0327 & 0.845 \\
\hline$\cdot|\cdot|$ & $.1 \cdot 1$ & 6 & 0.004 & 0.008 & 2.0333 & 0.917 \\
\hline
\end{tabular}

Source: Extracted from E-view Window 7.

As show in Table 5, Q-statistics up to lag 6 are not significant as revealed by their corresponding probability values. Therefore, the null hypothesis of no autocorrelation cannot be rejected strongly indicating that the series of market returns are not linearly dependent just as the steps of a drinker.

\subsection{The Runs and Kolmogorov-Sminov (K-S) Test}

These two no-parametric tests are also conducted in this study. The summary of their outcomes are presented in Table 6.

Table 6. Showing results of the runs and K-S tests

\begin{tabular}{llc}
\hline Test type & Z-statistic & Asymp-sig. \\
\hline Runs & -2.10 & 0.04 \\
K-S & 0.58 & 0.89 \\
\hline
\end{tabular}

Source: Extracted from SPSS Windom 19.

The observed Z-statistics for Runs and K-S tests are approximately 2.10 and 0.58 in absolute terms as revealed in Table 6. While the critical Z-statistic obtained at $5 \%$ is 1.64 . This suggests that in the Runs test the null hypothesis of randomity can be rejected. Also, the hypothesis of normality cannot be rejected in the K-S Test. Therefore, the two tests substantially oppose the weak form efficient theory.

\section{Conclusion}

In this study, we re-examine the positions or conclusions of different authors, particularly in Nigeria on the tests of RWH using a battery of tests: the ADF, PP, KPSS, JB, and BJ, K-S and Geary/Runs tests. We also adopt 
autocorrelation and serial correlation tests in our investigation. All of these tests except the unit root, Runs and $\mathrm{K}-\mathrm{S}$ tests jointly agree that there is presence of random-walk in the behaviour of stock returns. This is in tandem with the foundational work of Fama (1965) in American stock market and in recent time with the studies of Richard, Suchi and Ranghunandan (2010) in Nigeria but contradicts the study of Elango and Hussein (2008) in GCC countries. Thus, based on our findings, the controversial issue on the tests of RWH strongly relies on the test methods that are applied. We therefore recommend that more sophisticated techniques with asymptotically large data set should be applied in further studies.

\section{References}

Aguebor, S. O. N., Adewole, A. P., \& Maduegbuna, A. N. (2010). A random walk model for stock market prices. Journal of Mathematics and Statistics, 6(3), 342-346. http://dx.doi.org/10.3844/jmssp.2010.342.346

Amihud, Y., Mendelson, H., \& Lauterbach, B. (1997). Market microstructure and securities values: Evidence from Tel Aviv Stock Exchange. Journal of Financial Economics, 45, 365-390. http://dx.doi.org/10.1016/S0304-405X(97)00021-4

Appiah-Kusi, J., \& Menyah, K. (2003). Return predictability in African stock market. Review of Financial Economics, 12, 247-270. http://dx.doi.org/10.1111/j.1468-5957.1986.tb00522.x

Belaire-Franch, J., \& Opong, K. K. (2005b). Some evidence of random walk behaviour of Euro exchange rates using ranks and signs. Journal of Banking and Finance, 29, 1631-1643. http://dx.doi.org/10.1016/j.jbankfin.2004.06.031

Bera, A. K., \& Jarque, C. M. (1981). An efficient large-sample test for normality of observations and regression residuals. Working Papers in Econometrics 40. Australian National University, Canberra. http://dx.doi.org/10.1016/0165-1765(80)90024-5

Box, G. E. P., \& Jenkins, G. M. (1976). Time series analysis: Forecasting and control (2nd ed.). San Francisco: Holden-Day. http://dx.doi.org/10.1214/ss/1023799000

Box, G. E. P., \& Pierce, D. A. (1970). Distributions of residual autocorrelations in autoregressive integrated moving average models. Journal of the American Statistical Association, 65, 1509-1526. http://dx.doi.org/10.1016/j.jeconom.2010.01.006

Chang, Y. C., Fok, R. C. W., \& Lung, P. P. (2006). An examination of random walk hypothesis for gold prices. Working Paper, National Chung Hsing University, Taiwan, China.

Claessens, S., Dasgupta, S., \& Glen, J. (1995). Return behavior in emerging stock market. The world Bank Economic Review, 9(1), 131-151. http://dx.doi.org/10.1093/wber/9.1.131

Conrad, K., \& Juttner, D. J. (1973). Recent behavior of stock market prices in Germany and the random walk hypothesis. Kyklos, 26, 576-599. http://dx.doi.org/10.1111/j.1467-6435.1973.tb01882.x

Cootner, P. (1962). Stock prices: Random vs. systematic changes. Industrial Management Review, 3, 24-45.

Dickinson, J. P., \& Muragu, K. (1994). Market efficiency in developing countries: A case study of the Nairobi stock exchange. Journal of Business Finance and Accounting, 21(1), 133-150. http://dx.doi.org/10.1111/j.1468-5957.1994.tb00309.x

Elango, R., \& Hussein, M. I. (2008). An empirical analysis on the weak-form efficiency of the GCC markets applying selected statistical tests. International Review of Business Research Papers, 4(1), 140-159.

Fama, E. F. (1965). The behaviour of stock market prices. Journal of Business, 38, 34-105. http://dx.doi.org/10.1086/294743

Fama, E. F. (1970). Efficient capital markets: A review of theory and empirical test. Journal of Finance, 25, 382-417.

Fama, E. F. (1991). Efficient capital markets II. Journal of Finance, 46, 1575-1671.

Fama, E. F., \& French, K. (1988). Permanent and temporary component of stock prices. Journal of Political Economy, 96, 246-273. http://dx.doi.org/10.1086/261535

Granger, C. W. J. (1975). A survey of empirical studies on capital markets. In E. J. Elton \& M. J. Gruber (Eds.), International Capital Markets, 3-36.

Granger, C. W. J., \& Morgerstern, O. (1963). Spectral analysis of New York stock market prices. Kyklos, 16, 1-27. http://dx.doi.org/10.1111/j.1467-6435.1963.tb00270.x 
Gupta, R., \& Basu, P. K. (2007). Weak form efficiency in Indian stock markets. International Business \& Economics Research Journal, 6. http://dx.doi.org/10.2307/2109850

Hameed, A., \& Ashraf, H. (2009). Stock market volatility and weak-form efficiency: Evidence from an emerging market. International Journal of Business and Emerging Markets, 1(3), 249-263. http://dx.doi.org/10.1504/IJBEM.2009.023445

Hamid, K., Suleman, M. T., Shah, S. Z. A., \& Akash, R. S. I. (2010). Testing the weak form of efficient market hypothesis: Empirical evidence from Asia-Pacific markets. International Research Journal of Finance and Economics, 58,121-133.

Hawawini, G. A. (1984). European equity markets: A review of the evidence on price behaviour and efficiency (pp. 3-80).

Hsieh, D. (1991). Chaos and nonlinear dynamics: Application to financial market. Journal of Finance, 46, 1839-1877. http://dx.doi.org/10.1111/j.1540-6261.1991.tb04646.x

Inegbedion, H. E. (2009). Efficient market hypothesis and the Nigerian capital market. An Unpublished M Sc. Thesis, University of Benin, Nigeria.

Kendall, M. G. (1943). The advanced theory of statistics (Vol. 1). London: Griffin. http://dx.doi.org/10.2307/2980947

Kendall, M. G. (1953). The analysis of economic time series part 1 prices. Journal of the Royal Statistical Society, 96(1), 11-25. http://dx.doi.org/10.2307/2980947

Kim, J. H., \& Shamsuddin, A. (2008). Are Asian stock markets efficient? Evidence from new multiple variance ratio tests. Journal of Empirical Finance, 15(3), 518-532. http://dx.doi.org/10.1016/j.neuroimage.2008.08.019

Kolmogorov, A. (1933). Sulla determinazione empirica di una legge di distribuzione. Ist. Ital. Attuari, 4, 83.

Laurence, M. M. (1986). Weak-form efficiency in the Kuala Lumpur and Singapore stock markets. Journal of Banking and Finance, 10, 431-445. http://dx.doi.org/10.1016/S0378-4266(86)80031-0

Liu, T. (2010). Stock market development and market efficiency on China stock market. Middle Eastern Finance and Economics.

Ljung, G. M., \& Box, G. E. P. (1978). On a measure of lack of fit in time serials models. Biometrical, 65(2), 297-303. http://dx.doi.org/10.1093/biomet/65.2.297

Lo, A. (1997). Market efficiency: Stock market behavior in theory and practice. Cheltenham: Edward Elgar Publishing Company.

Lo, A. W., \& Mackinlay, A. C. (1989). The size and power variance ratio test in finite samples: A monte carlo investigation. Journal of Econometries, 40, 203-238. http://dx.doi.org/10.1016/0304-4076(89)90083-3

Lo, A.W., \& Mackinlay, A. C. (1988). Stock market prices do not follow random walks: Evidence from a simple specification test. The Review of Financial Studies, 1(1),41-66. http://dx.doi.org/10.1093/rfs/1.1.41

Mishra, P. K., Das, K., B., \& Pradhan, B. B. (2009). Empirical evidence on Indian stock market efficiency in context of the global financial crisis. Global Journal of Finance and Management, 1(2), 149-157.

Nicolaas, G. (1997). Share market efficiency: Tests using daily data for Australia and New Zealand. Applied Financial Economics, 7, 645-657. http://dx.doi.org/10.1080/758533856

Nourredine, K. (1998). Behaviour of stock prices in the Saudi Arabian financial market: Empirical research findings. Journal of Financial Managemen \& Analysis, 11(1), 48-55.

Olowe, R. A. (1999). Weak form efficiency of the Nigerian stock market: Further evidence. African Development Review, 11(1), 54-68. http://dx.doi.org/10.1111/1467-8268.00003

Osborne, M. F. M. (1962). Periodic structure in the Brownian motion in the stock prices. Operation Research, 345-379. http://dx.doi.org/10.1287/opre.10.3.345

Parkinson, J. M. (1984). The Nairobi stock exchange in the context of development of Kanya. Savings and Development, 8(4), 363-370.

Poshakwale, S. (1996). Evidence on weak form efficiency and day of the week effect in the Indian stock market. Finance India, 10(3), 605-616. 
Poterba, J. M., \& Summers, L. H. (1988). Mean reversion in stock prices: Evidences and implications. Journal of Financial Economics, 22(1), 27-59. http://dx.doi.org/10.1016/0304-405X(88)90021-9

Rapuluchukwu, E. U. (2010). The efficient market hypothesis: Realities from the Nigerian Stock Market. Global Journal of Finance and Management, 2(2), 321-331.

Reilly, F. K., \& Brown, K. C. (2003). Investment Analysis and Portfolio Management. Ohio United States of America: Thomson South-Western.

Samuels, J. M., \& Yacout, N. (1981). Stock exchange in developing countries. Savings and Development, 5(4), 213-230.

Samuelson, P. (1965). Proof that properly anticipated prices fluctuate randomly. Industrial Management Review, $6,41-49$

Siegel, S. (1956). Non-parametric Statistics for Behavioral Sciences. New York: McGraw-Hill Company.

Simons, D., \& Laryea, S. A. (2004). Testing the efficiency of selected African stock markets. Working Paper.

Smirnov, N. V. (1948). Tables for estimating the goodness of fit of empirical distributions. Annals of Mathematical Statistics, 19, 279. http://dx.doi.org/10.1214/aoms/1177730256

Working, H. (1934). A random difference series for use in the analysis of time series. Journal of the American Statistical Association, 29, 11-24. http://dx.doi.org/10.1080/01621459.1934.10502683

Working, H. (1960). Note on the correlation of first differences of averages in a random chain. Econometrica, 28, 916-918. http://dx.doi.org/10.2307/1907574

Wright, J. H. (2000). Alternate variance-ratio tests using ranks and signs. Journal of Business and Economic Statistic, 18, 1-9.

\section{Copyrights}

Copyright for this article is retained by the author(s), with first publication rights granted to the journal.

This is an open-access article distributed under the terms and conditions of the Creative Commons Attribution license (http://creativecommons.org/licenses/by/3.0/). 